\title{
Análise de permeabilidade em modelo reduzido de barragem através da altura piezométrica
}

Apresentando-se como uma das obras de maiores complexidades da engenharia civil, as barragens são elementos estruturais construídos ao longo do eixo transversal, em direção ao escoamento de um curso d'água, designada a ser um reservatório artificial. Atendendo basicamente a dois desígnios: regularização e retenção. Seguindo os preceitos, essa pesquisa tem como finalidade a criação de protótipos físicos reduzidos, simulando barragens de terra a fim de analisar alguns dos fenômenos que ocorrem nas mesmas. A construção será realizada com solo arenoso e argiloso, em alguns dos experimentos será apenas utilizado solo arenoso e em outros, a mistura desses dois solos em diversas proporções. Possuindo como fim principal, a análise de como será o comportamento da água diante da relação entre os solos, a fim de realizar as leituras piezométricas. As leituras serão realizadas a partir do enchimento da barragem com o marco de 0 minuto e, posteriormente feitas a cada 5 minutos, totalizando 10 leituras. Foram realizados sete experimentos no total, sendo um de calibração do equipamento e seis com a construção do modelo reduzido da barragem. Portanto este trabalho tem por intenção avaliar o controle de fluxo interno através do corpo da barragem (dimensionamento do sistema de drenagem interna) através de um modelo reduzido em laboratório.

\section{Permeability analysis in reduced dock models through piezometric height}

Introducing itself as one of the most complex works of civil engineering, as dams are built along the transverse axis, towards the flow of a watercourse, designe as an artificial reservoir. Serving basically two desios: regularization and retention. Following the precepts, this research has as objective the creation of reduced physical prototypes, simulating earth dams and end of analysis of some of the phenomena that occur in them. The construction will be done with sandy and clayey soil, since the experiments will only be used in various proportions. In order to perform the analysis of a main method, an analysis of how the behavior of the water between the soils will be in order to perform the piezometric readings. As the exits were done every 5 minutes, totaling 10 readings. For the expanded the total capacity of the measurement and the barracation and the measurement of the barrage and the measurement of the barrage and heavy metal system. a reduced model in the laboratory.

Keywords: Percolation; Earth Dams; Physical Model; Piezometer

Topic: Engenharia Geotécnica

Reviewed anonymously in the process of blind peer

Kharlla Rhobertta Correia

Faculdade Presidente Antônio Carlos, Brasil http://lattes.cnpq.br/8407313574184195

correiaengenharia@outlook.com

Talita Caroline Miranda

Faculdade Presidente Antônio Carlos, Brasil

http://lattes.cnpq.br/7173437103345457

talitamiranda@itpacporto.com.br

Carita Monielle Maia de Oliveira

Faculdade Presidente Antônio Carlos, Brasil

http://lattes.cnpq.br/4130731603348401

caritaoliveira@itpacporto.com.br
Received: 14/06/2018

Approved: 24/09/2018
Mateus Borba Teixeira

Faculdade Presidente Antônio Carlos, Brasil

http://lattes.cnpq.br/7066869794283823

correiaengenharia@outlook.com
Referencing this:

CORREIA, K. R.; MIRANDA, T. C.; OLIVEIRA, C. M. M.; TEIXEIRA, M. B. Análise de permeabilidade em modelo reduzido de barragem através da altura piezométrica. Engineering Sciences, v.6, n.2, p.32-42, 2018. DOI: http://doi.org/10.6008/CBPC2318-3055.2018.002.0004

DOI: 10.6008/CBPC2318-3055.2018.002.0004 


\section{INTRODUÇÃO}

Segundo Quintas (2002), obras de barragens, são aquelas que interceptam um curso d'água com a finalidade essencial é de retenção de certo volume de água para diferentes usos. $O$ tipo de barragem mais comum no Brasil é o de barragem de terra e enrocamento, correspondendo a $82 \%$ do total, sendo os $18 \%$ restantes de barragens de concreto (SAYÃO, 2009). A barragem de terra é a mais comum no Brasil, por se ter vales muito largos e ombreiras suaves, necessitando de grandes extensões de crista, ao mesmo tempo em que se dispõe abundantemente de solo anteriormente, além de serem indicadas para fundação de qualquer tipo, solo ou rocha (MENDONÇA, 2012).

Para a construção de barragens de terra há a necessidade de grande quantidade de material para a elaboração do núcleo (material argiloso), espaldares, filtros e drenos. Além disso, as barragens de terra são as que mais demandam estudos geotécnicos, segundo Souza (2013) o projeto de barragem de terra e enrocamento devem possuir os seguintes itens de estudo: (i) controle de fluxo através do corpo da barragem (dimensionamento do sistema de drenagem interna), controle de fluxo pelas fundações (tratamento do terreno de fundação) e controle de fluxo nas interfaces; (ii) estabilidade dos taludes de montante e jusante (análise de estabilidade para todas as situações possíveis); (iii) análise de compatibilidade das deformações e, (iv) proteção contra erosão superficial dos taludes (dimensionamento do sistema de drenagem superficial).

Muitas vezes para a análise do projeto de barragem utilizam-se da representação de um fenômeno por meio de modelos reduzidos, estes modelos baseados em leis de semelhança. Para a correta modelação é necessário que seja representado o fenômeno em questão, de forma confiável (KANASHIRO et al., 2013), ou seja, além da semelhança geométrica é necessário o conhecimento do mecanismo que o rege o fenômeno analisado. Marques et al. (2010) demonstraram que através da análise em modelo reduzido de barragens de terra constituídas com elementos drenantes ou núcleos centrais, verifica-se a diferença entre o controle do escoamento pela capacidade de drenagem do sistema ou pela dissipação da energia potencial trazida pela água que circula no meio poroso.

O número de barragens de terra tende a crescer, visto que, uma das formas de tornar a nossa agricultura menos dependente das condições atmosféricas é a prática da irrigação, que consequentemente está diretamente ligada às técnicas de produção de água na bacia hidrográfica (VALVERDE et al., 2014). Portanto a 'produção de água' como um processo de aumento da quantidade e qualidade da água, bem como da estabilização ou regularização desta quantidade de água ao longo do ano, deve ocorrer para fins de irrigação (VALENTE et al., 2001).

O Brasil se tornou um dos líderes mundiais no agronegócio, e isso foi possível por causa da disponibilidade dos recursos hídricos, das condições de solo e clima, de resultados de pesquisas, do empreendedorismo da agroindústria e de políticas de governo. A vasta região do Cerrado localizada no Norte-Nordeste brasileiro denominada Matopiba - Maranhão, Tocantins, Piauí e Bahia - vem sendo incorporada à produção e se consolida como importante fronteira agrícola (BOLFE et al., 2016). Neste contexto há a previsão de aumento do uso da água para irrigação na cidade de Porto Nacional, no estado do 
Tocantins, localizada na região do Matopiba, consequentemente haverá o aumento de construções de barragens de terra para retenção de água para fins de irrigação.

A vantagem dos modelos reduzidos é a possibilidade de efetuar observações em sistemas de menores dimensões, mas de comportamento semelhante, e de forma mais rápida que no sistema natural cujo comportamento se quer analisar. Contudo, o conceito de semelhança física apresenta dois conceitos básicos, um conceito qualitativo e um conceito quantitativo; conforme Ribeiro (2000): (i) aspecto qualitativo - confia no fato que o mesmo fenômeno e as mesmas grandezas que forem pautadas pela mesma lei, se passam tanto no modelo reduzido quanto no modelo real; (ii) aspecto quantitativo - admite a existência de relações fiéis bem conhecidas e independentes dos valores particulares das elevações entre os valores que ocorrem no modelo e os que ocorrem no protótipo.

Portanto este trabalho tem como finalidade avaliar o controle de fluxo interno através do corpo da barragem (dimensionamento do sistema de drenagem interna) através de um modelo reduzido em laboratório. Para a construção do modelo utilizou-se uma mistura de solo (areia e argila) com o intuito de avaliar a influência na altura piezométrica com a mudança de granulometria.

\section{METODOLOGIA}

Para a construção do modelo reduzido foi utilizado o equipamento para estudo de escoamento de água com superfície livre o Canal Aberto XL06 da Labitrix. O mesmo consiste em um canal construído em vidro temperado transparente que permite a visualização do escoamento, acidentes e dispositivos hidráulicos, instrumentos de medição e um sistema de recirculação de água. Neste, o ajuste de vazão é realizado através de um inversor de frequência e de uma bomba trifásica, a medição de vazão é feita através de um rotâmetro e o ajuste de declividade do canal através de um fuso motorizado com controle através de botoeiras elétricas. A alimentação é sempre em 220Vac monofásico (Figura 1), sendo a espessura interna do canal de $10 \mathrm{~cm}$ de largura.

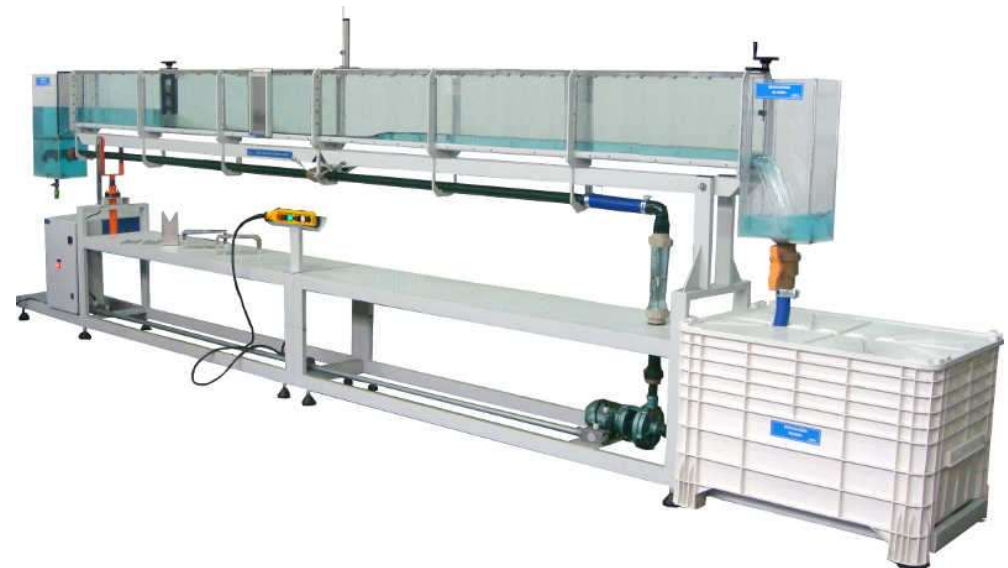

Figura 1: Equipamento utilizado para a realização do modelo reduzido. Fonte: Labitrix (2018).

A Figura 2 apresenta o fluxo metodológico utilizado para o desenvolvimento deste trabalho, detalhado no texto a seguir. Foram realizados 7 experimentos no total, sendo um de calibração do equipamento e seis com a construção do modelo reduzido da barragem, com as dimensões de $80 \mathrm{~cm}$ de 
comprimento, $23 \mathrm{~cm}$ de altura e $10 \mathrm{~cm}$ de largura, com $20 \mathrm{~cm}$ de crista e taludes de inclinação de $16^{\circ}$ (Figura 3). Adotou-se para todos os modelos a mesma seção típica, compactadas com a mesma energia, ambiente controlado de temperatura e as leituras de piezométricas realizadas com a comporta de fundo com sete orifícios para a leitura piezométrica, ligados por mangueira transparentes ao piezômetro (Figura 4).

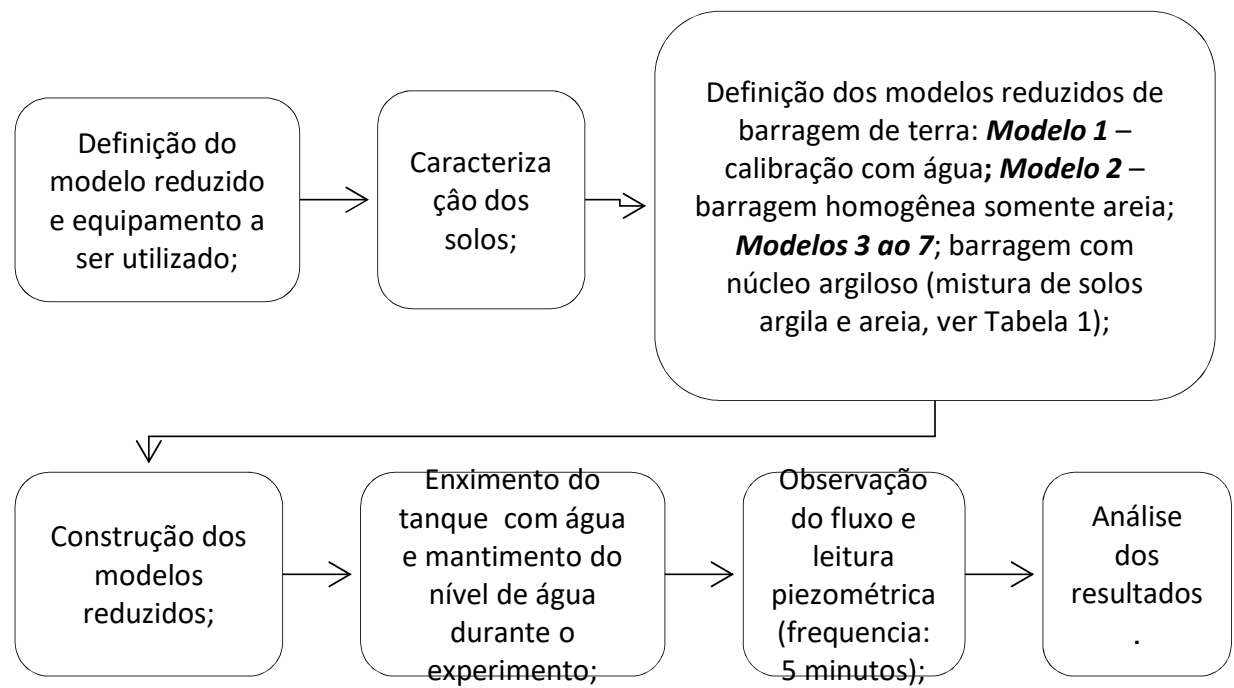

Figura 2: Passo a passo do experimento realizado.

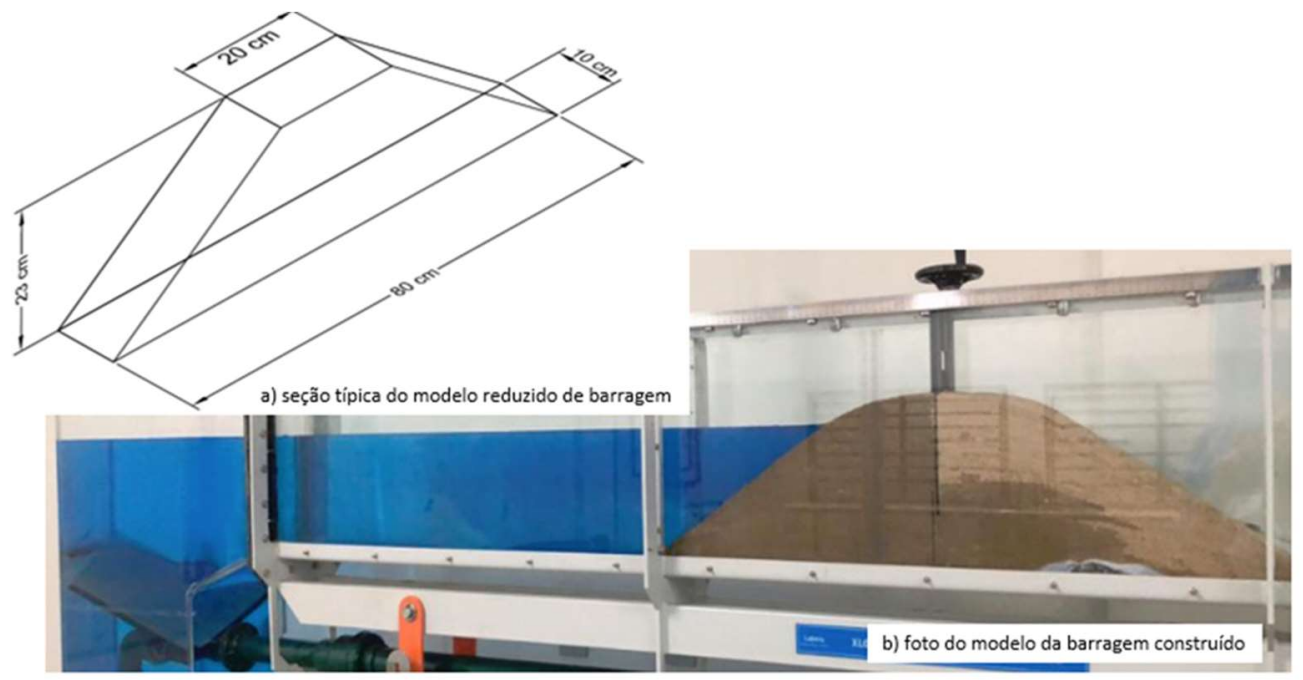

Figura 3: Modelo Reduzido: seção típica e modelo construído.

Para a construção do primeiro modelo foi utilizado apenas solo arenoso. Já para a construção dos cinco demais modelos adotou-se um núcleo central na barragem (com $30 \%$ das dimensões totais do modelo - Figura 2), contendo cinco misturas de solos, com diferentes porcentagens de argila e areia. A Tabela 1 apresenta as porcentagens de argila adotadas com a intenção de avaliar a influência, na permeabilidade da barragem, a partir da inclusão de solos finos. Esta influência foi avaliada através da leitura piezométrica, após o enchimento e percolação do fluxo de água no corpo da barragem. As leituras iniciaram a partir do início do enchimento do reservatório, e tomadas a cada cinco minutos, até completar dez leituras. A cota máxima de enchimento do reservatório foi de $22 \mathrm{~cm}$ e manteve-se nesta cota durante todo o experimento e leituras. 


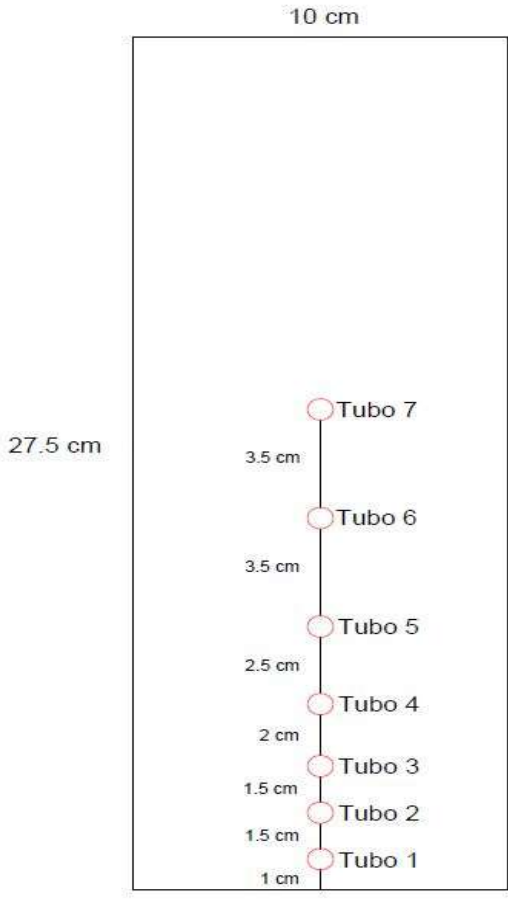

a) Comporta de fundo

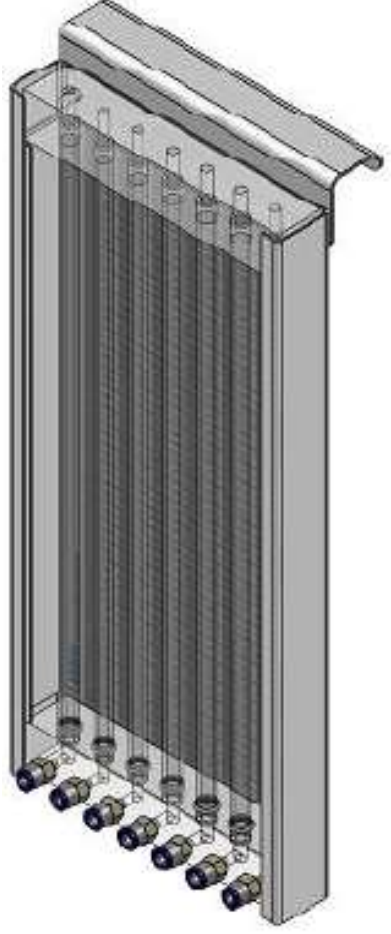

b) Piezômetros

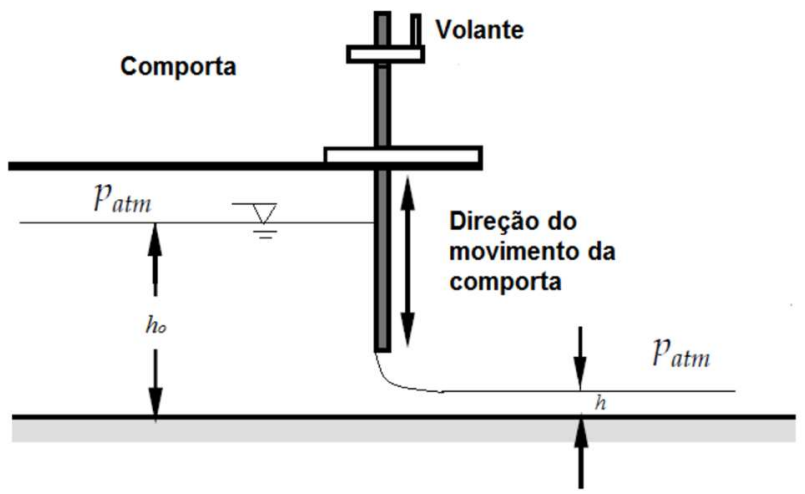

c) Comporta de fundo em descarga livre, calibração das leituras piezométricas.

Figura 4: Itens utilizados para avaliação da pressão da água no corpo de uma barragem. Fonte: Adaptado de Labitrix (2018).

Tabela 1: Relação em porcentagem das misturas dos solos utilizados no núcleo central da barragem, que corresponde a $30 \%$ das dimensões totais do modelo reduzido.

\begin{tabular}{lll} 
Modelo & \% de areia & \% de argila \\
\hline 0 & 0 & 0 \\
1 & 100 & 0 \\
2 & 95 & 5 \\
3 & 85 & 15 \\
4 & 70 & 30 \\
5 & 60 & 40 \\
6 & 10 & 90 \\
\hline
\end{tabular}

\section{DISCUSSÃO TÉORICA}

Conforme a Figura 4, a expectativa dos resultados das leituras piezométricas eram que fossem crescentes a partir do Tubo 7 até o Tubo 1 (ordem esperada das leituras Tubo $1>$ Tubo $2>$ Tubo $3>$ Tubo 4 $>$ Tubo 5 > Tubo 6 > Tubo 7), devido a diferença de altura da localização dos orifícios, sendo que no Tubo 1 esperava-se uma leitura de $190 \mathrm{~mm}$ de altura, visto que a distância do fundo barragem até o furo 1 é de $30 \mathrm{~mm}$ e a altura de cota de enchimento da barragem foi de $220 \mathrm{~mm}$. Para o furo 7 esperava-se uma leitura 
de $45 \mathrm{~mm}$, visto que o mesmo está distante $155 \mathrm{~mm}$ do furo 1 . As figuras de 5 a 11 apresentam os resultados das leituras piezométricas por modelo construído e o Quadro 1 evidencia os valores esperados de altura piezométrica e os valores reais obtidos em ensaio de laboratório. Incluindo da média dos valores esperados e obtidos.

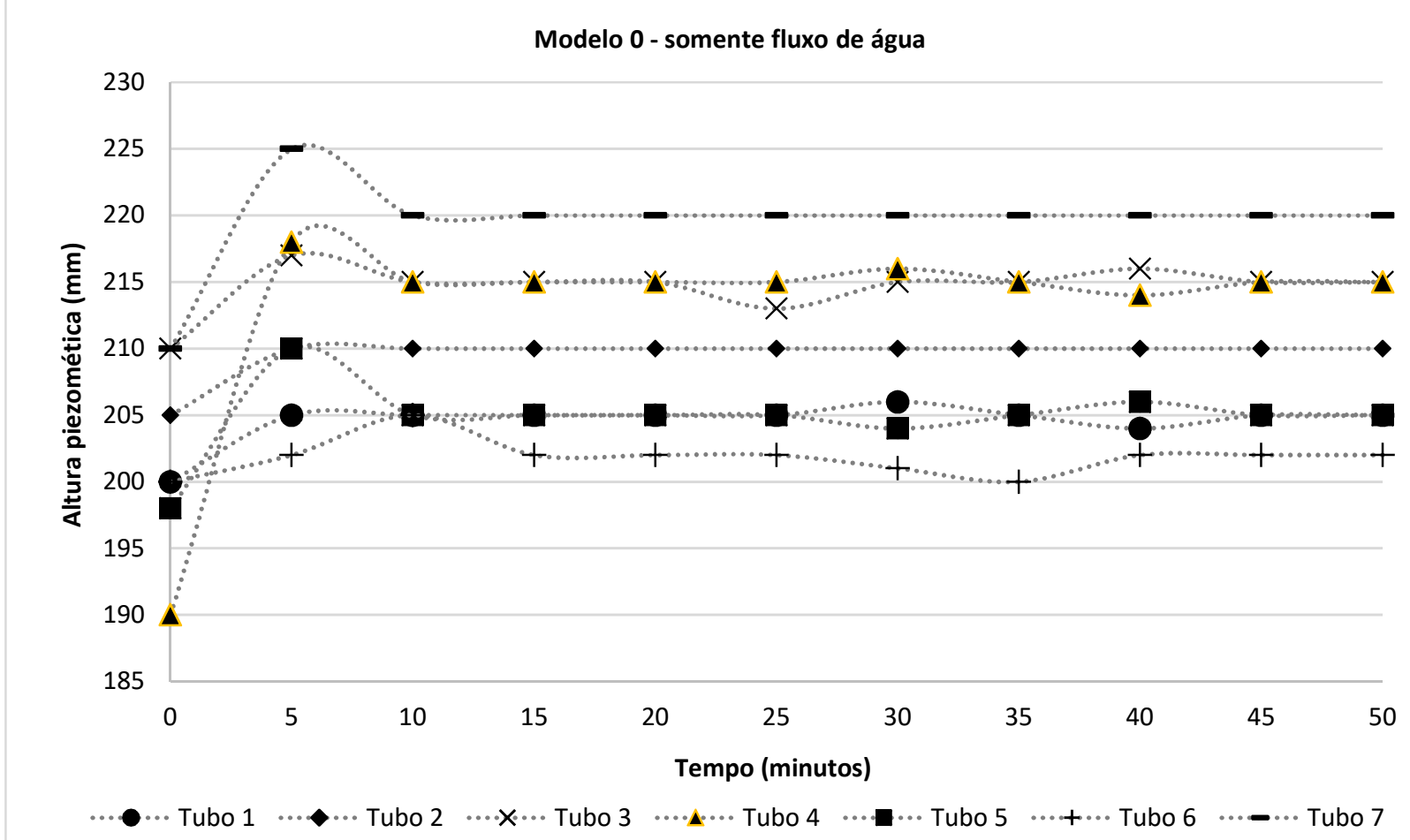

Figura 5: Resultado das leituras piezométricas no Modelo 0, calibração do canal somente com água.

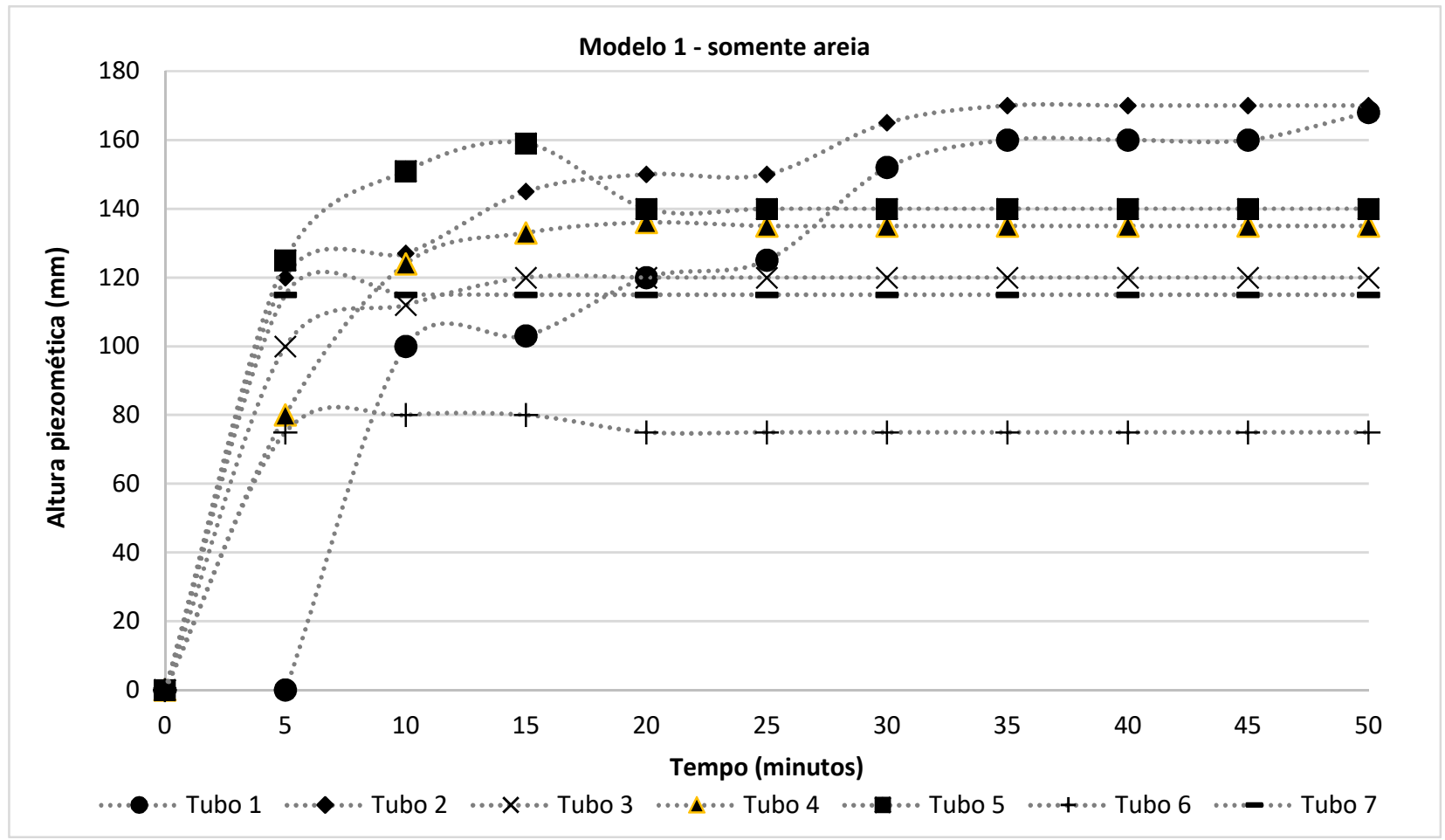

Figura 6: Resultado das leituras piezométricas no Modelo 1, barragem somente com areia. 


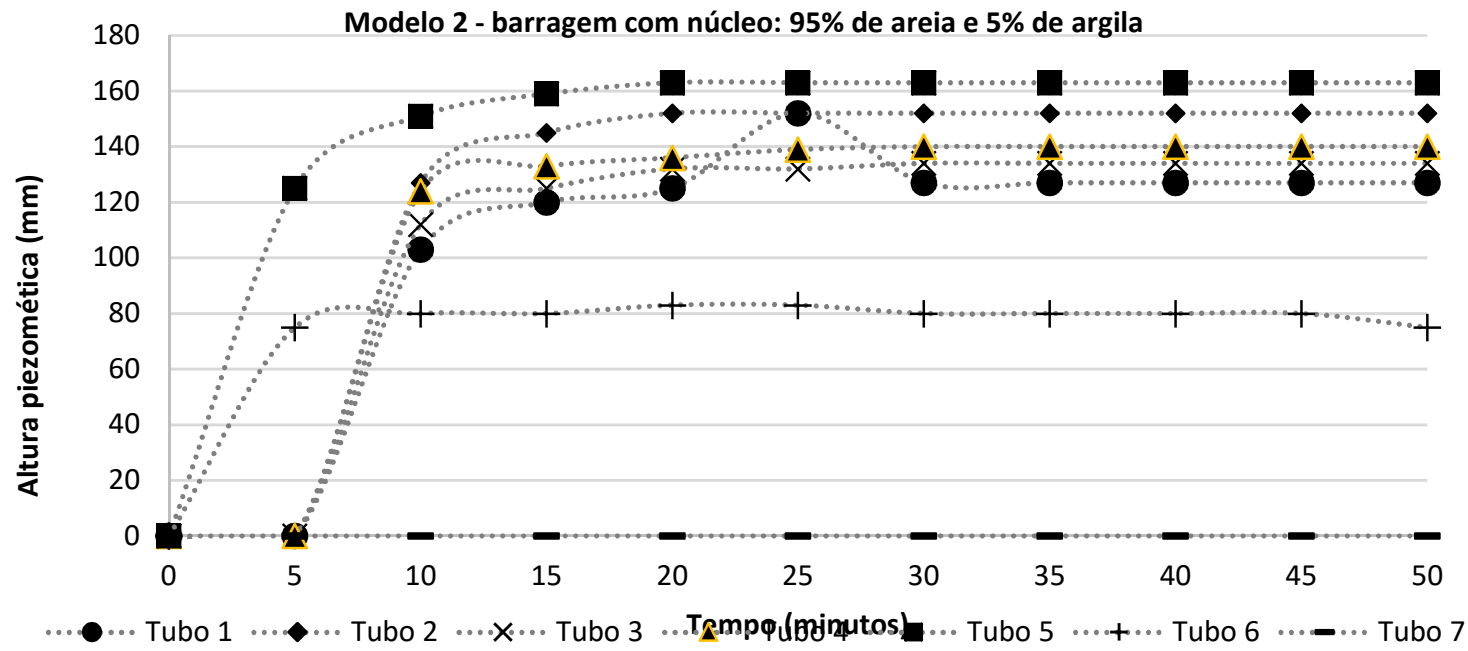

Figura 7: Resultado das leituras piezométricas no Modelo 2, barragem com núcleo de mistura de solo $95 \%$ de areia e $5 \%$ de argila.

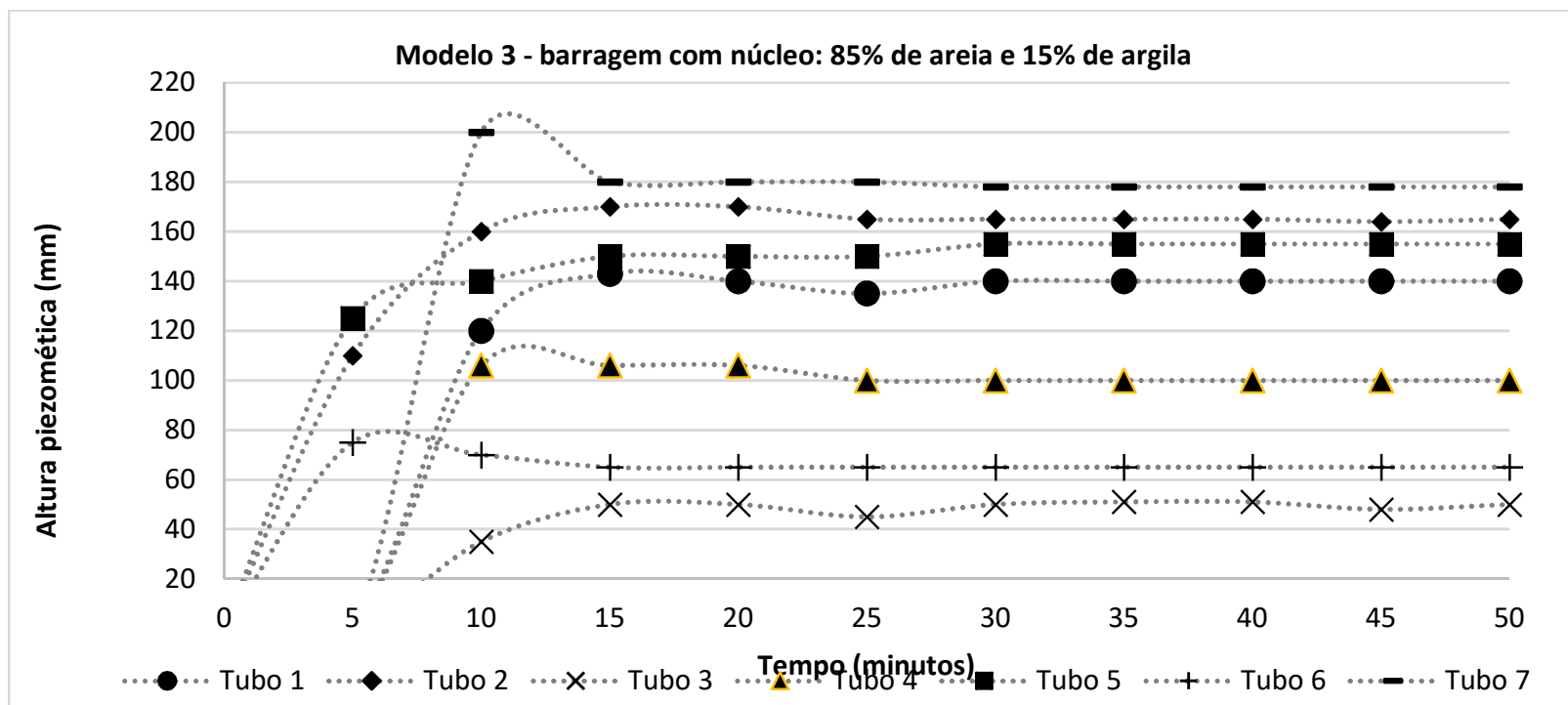

Figura 8: Resultado das leituras piezométricas no Modelo 3, barragem com núcleo de mistura de solo $85 \%$ de areia e $15 \%$ de argila.

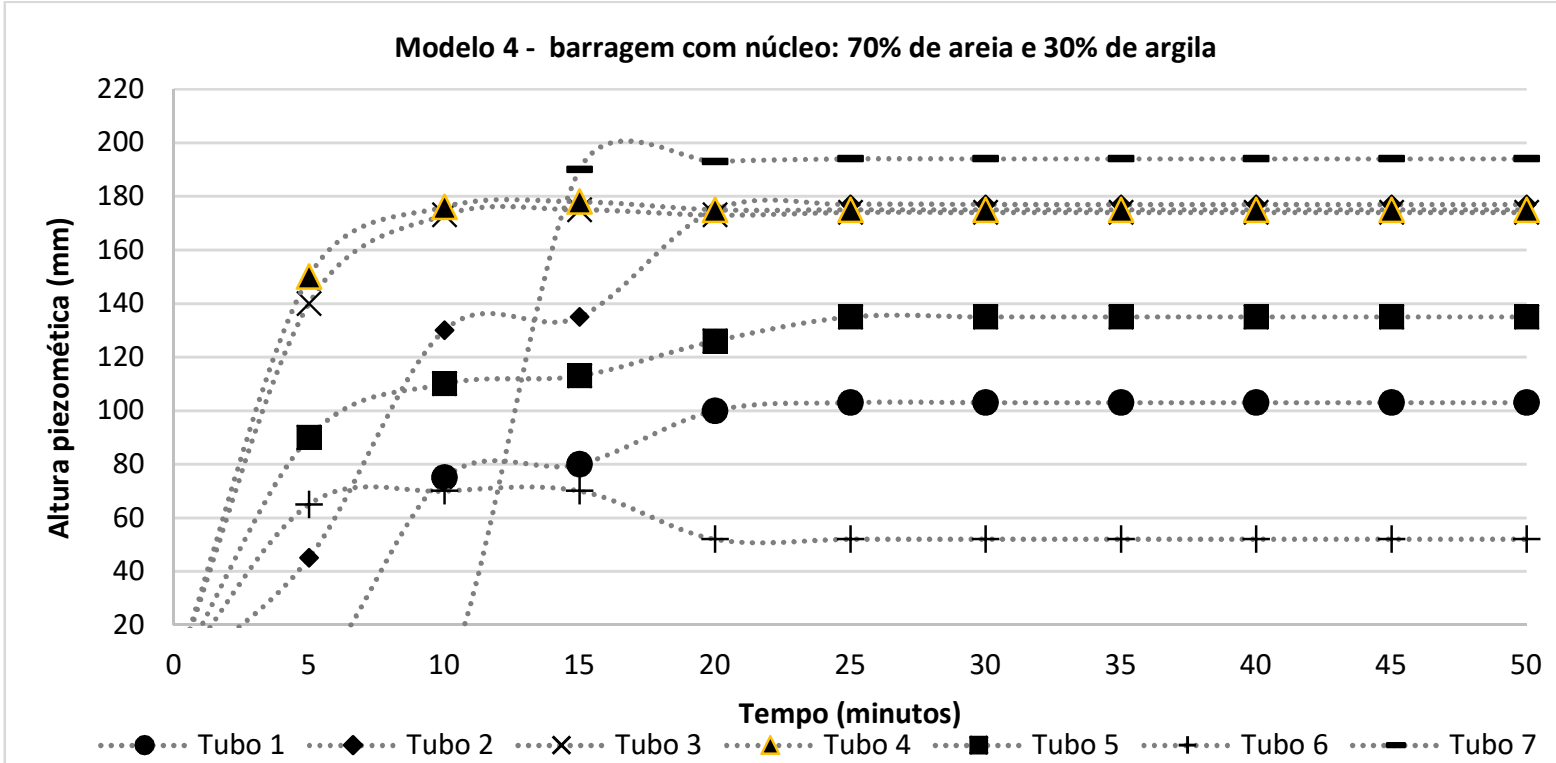

Figura 9: Resultado das leituras piezométricas no Modelo 4, barragem com núcleo de mistura de solo $70 \%$ de areia e $30 \%$ de argila. 


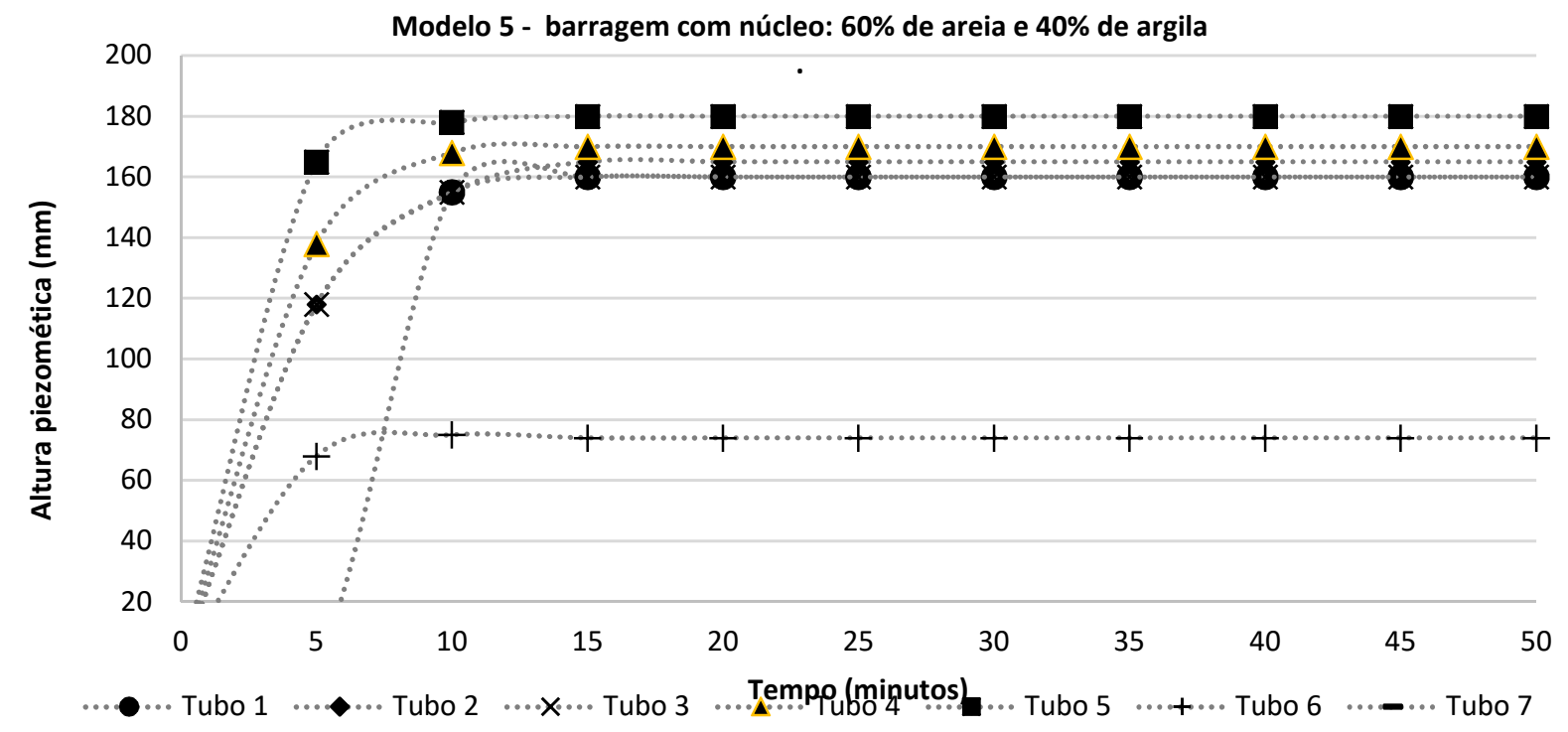

Figura 10: Resultado das leituras piezométricas no Modelo 5, barragem com núcleo de mistura de solo $60 \%$ de areia e $40 \%$ de argila.

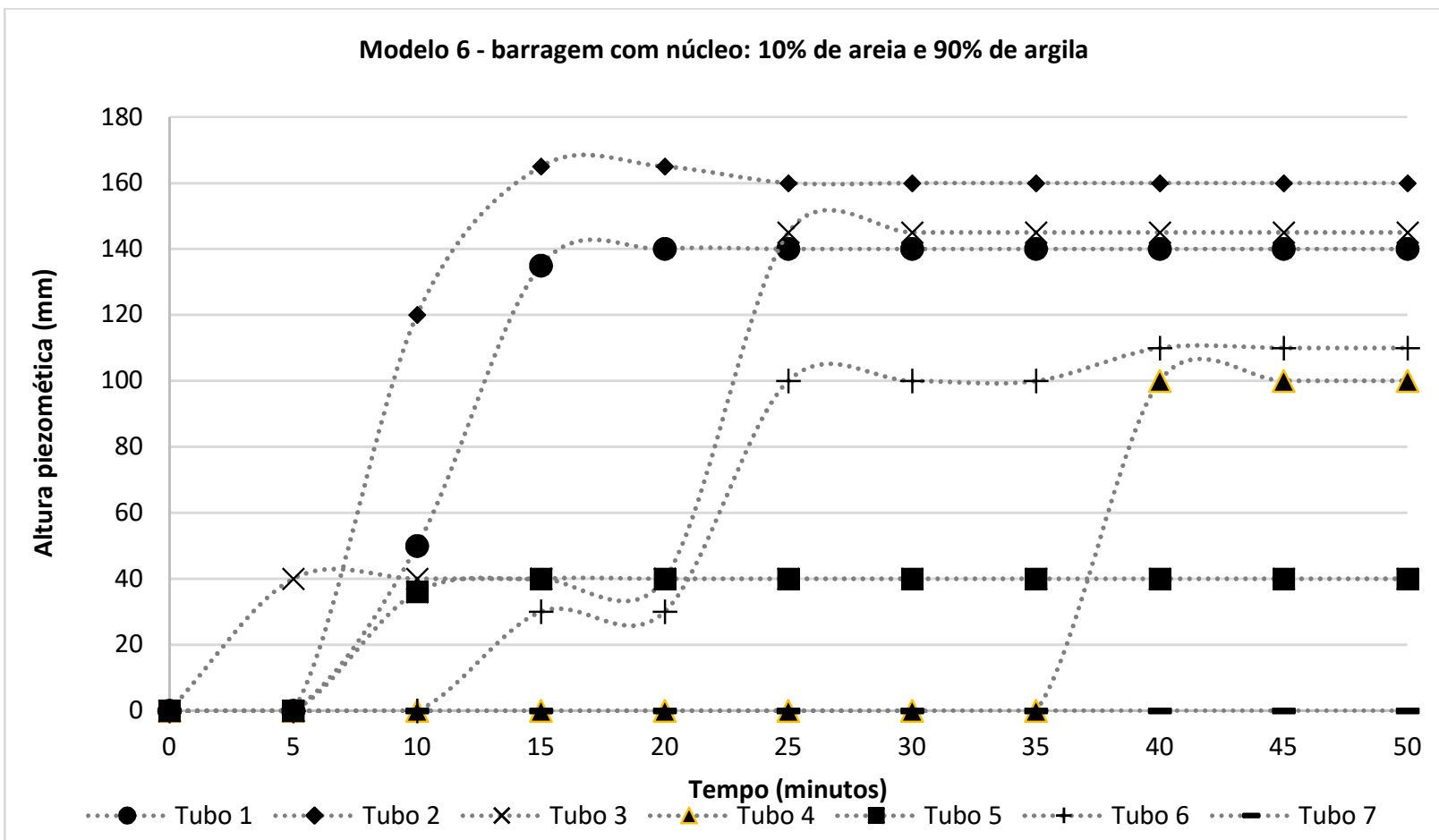

Figura 11: Resultado das leituras piezométricas no Modelo 6, barragem com núcleo de mistura de solo $10 \%$ de areia e $90 \%$ de argila.

Quadro 1: Valores esperados e valores obtidos.

\begin{tabular}{|l|l|l|l|l|l|l|l|}
\hline Ordem crescente esperada de leitura & Modelo 1 & Modelo 2 & Modelo 3 & Modelo 4 & Modelo 5 & Modelo 6 \\
\hline Tubo & Leitura $(\mathrm{mm})$ & Leitura $(\mathrm{mm})$ & Leitura $(\mathrm{mm})$ & Leitura $(\mathrm{mm})$ & Leitura $(\mathrm{mm})$ & Leitura $(\mathrm{mm})$ & Leitura $(\mathrm{mm})$ \\
\hline Tubo 7 & 45 & 202 & 75 & 0 & 50 & 52 & 0 \\
\hline Tubo 6 & 80 & 205 & 115 & 75 & 65 & 103 & 40 \\
\hline Tubo 5 & 115 & 205 & 120 & 127 & 100 & 135 & 100 \\
\hline Tubo 4 & 140 & 210 & 135 & 134 & 140 & 174 & 110 \\
\hline Tubo 3 & 160 & 215 & 140 & 140 & 155 & 175 & 140 \\
\hline Tubo 2 & 175 & 215 & 170 & 152 & 165 & 177 & 145 \\
\hline Tubo 1 & 190 & $\mathbf{2 2 0}$ & 170 & 163 & 178 & 194 & 160 \\
\hline Média & $\mathbf{1 2 9 , 3}$ & $\mathbf{2 1 0 , 3}$ & $\mathbf{1 3 2 , 1}$ & $\mathbf{1 1 3 , 0}$ & $\mathbf{1 2 1 , 9}$ & $\mathbf{1 4 4 , 3}$ & $\mathbf{9 9 , 3}$ \\
\hline
\end{tabular}

Contrariando as expectativas na Figura 5 (calibração do aparelho somente com água) contata-se que a menor medida se deu no Tubo 6 e não no Tubo 7, e apenas os Tubos 5 e 3 encontram na ordem esperada 
de leitura. Nota-se também que as leituras atingiram a estabilidade em cerca de 10 minutos para todos os tubos, com pequena variação das leituras no Tubo 6 entre 30 e 40 minutos e no Tubo 5 e 1 no intervalo de 30 minutos e de 40 minutos.

Já na Figura 6 os resultados do primeiro modelo reduzido de barragem constituído apenas de areia, identifica-se que a menor medida se deu no Tubo 6, com 75mm de altura, e apenas o Tubo 4 se encontrou na posição esperada de leitura. No entanto os Tubos 1 e 2 tiveram a maior leitura após a estabilização do fluxo de água. Em relação ao tempo de estabilização das leituras, verifica-se que as leituras atingiram a estabilidade em cerca de 30 minutos para todos os tubos, com pequena variação das leituras no Tubo 1 na leitura de 50 minutos. A Figura 7 apresenta os resultados do segundo modelo reduzido de barragem, com núcleo central contendo 95\% de areia e 5\% de argila. Observa-se que menor medida se deu no Tubo 7, com 0mm de altura, e os Tubos 7, 6, 4 e 2 possuem leitura na posição esperada. 0 tempo de estabilização das leituras se manteve igual ao modelo anterior em 30 minutos, com diminuição das leituras no Tubo 6 em 50 minutos.

Para o terceiro modelo reduzido de barragem os resultados das leituras piezométricas são apresentados na Figura 8, do modelo com núcleo central contendo 85\% de areia e 15\% de argila. Observa-se que menor medida se deu no Tubo 3, com $50 \mathrm{~mm}$ de altura, e apenas o Tubo 6 se manteve na posição esperada de leitura. Já neste modelo repara-se que o tempo de estabilização das leituras diminuiu para 15 minutos, com pequena variação de leitura nos Tubo 2, 3, 4 e 5 em 25 minutos.

Nota-se que na Figura 9 os resultados do quarto modelo reduzido de barragem, com núcleo central contendo $70 \%$ de areia e $30 \%$ de argila, que a menor medida se deu no Tubo 6, com $52 \mathrm{~mm}$ de altura e os Tubos 5 e 2 se mantiveram nas posições esperadas de leitura. Já neste modelo observa-se que o tempo de estabilização das leituras aumentou para 25 minutos, sem variação nas demais leituras. A Figura 10 apresenta os resultados do quinto modelo reduzido de barragem, com núcleo central contendo $60 \%$ de areia e $40 \%$ de argila. Nota-se que menor medida se deu no Tubo 7, com 0mm de altura e os Tubos 7 e 6 se mantiveram nas posições esperadas de leitura. Constata-se que as leituras do modelo se estabilizaram com 10 minutos, sem variação considerável nas demais leituras.

O sexto modelo reduzido de barragem, verificado na Figura 11, com núcleo central contendo $10 \%$ de areia e $90 \%$ de argila. Atenta-se que menor medida se deu no Tubo 7, com $0 \mathrm{~mm}$ de altura e apenas este se manteve na posição esperada. 0 tempo de estabilização deste modelo se deu aos 40 minutos, muito acima do tempo verificado nos modelos anteriores. O Tubo 4 teve alteração no minuto 50 . Observando as médias das leituras realizadas nos modelos (Quadro 1), constata-se uma redução das alturas piezométicas, diminuindo de 210,3mm para 99,3mm do Modelo 1 e o Modelo 6, no entanto não segue a mesma tendência nos modelos intermediários.

\section{CONCLUSÕES}

Na maioria das vezes usa-se a modelagem física para complemento de cálculos matemáticos para um projeto de grande extensão e complexibilidade. Sendo assim, no modelo físico é possível analise dos 
fenômenos para calibração dos modelos matemáticos. Leonardo da Vinci e Arquimedes já haviam realizado estudos sobre modelos reduzidos, no entanto a construção destes somente foi possível após a descoberta da Teoria da Semelhança com o Teorema de Buckingham, com autoria de Isaac Newton (MELO, 2011). Na modelagem física, há dois fenómenos que demandam um especial cuidado na escolha das escalas a ser tomado, o escoamento superficial sobre a jusante da barragem e o escoamento de percolação no interior do corpo da barragem (FRANCA, 2002).

Neste contexto, os resultados de leituras piezométricas obtidos, não ficaram dentro do esperado pelas leis de condutividade hidráulica e dos vasos comunicantes. Esperava-se a maior leitura no Tubo 1 (com maior altura de coluna de água) e a menor leitura no Tubo 7 (com menor altura de coluna de água). Uma das hipóteses para o ocorrido é de que as ligações das mangueiras com os orifícios não estavam bem vedados e, por estarem enterrados no corpo da barragem, não foi possível verificar se havia vazamento, entrada de ar ou entupimento. Sendo estes fatores influenciadores diretos na leitura piezométrica. Além disso, não se levou em consideração a temperatura da água e sua viscosidade. Outra hipótese é de que a escolha das escalas tomadas e da escolha de um núcleo central de mistura de solo (areia e argila) em apenas 30\% do volume total não sejam representativos, tenham influenciado nos resultados obtidos.

No entanto, identifica-se que ao considerar as médias das leituras piezométricas por modelo, há uma influência direta da quantidade de argila e areia dos modelos, pois nenhum dos modelos contendo grãos finos de argila, chegou a atingir o valor médio de leitura em comparação ao Modelo 1, composto por $100 \%$ de areia. Após o término deste trabalho fica claro que os modelos reduzidos são de difícil calibração e que nem sempre os resultados esperados são os resultados obtidos, no entanto é necessário complementar o estudo com os resultados da caracterização geotécnica dos solos, com ensaios de granulometria, limites de Attenberg e de permeabilidade. Além disso, incluir uma modelagem numérica do fluxo de água no corpo da barragem, para só assim encontramos justificativas para o ocorrido.

\section{REFERÊNCIAS}

BOLFE, E.; VICTÓRIA, D. C.; CONTINI, E.; BAYMA-SILVA, G.; SPINELLI-ARAUJO, L.. Matopiba em crescimento agrícola Aspectos territoriais e socioeconômicos. 2016.

FRANCA, M. J. R. P.. Caracterização e Modelação numérica e experimental da ruptura provocada por galgamento de barragens de enrocamento. Dissertação (Mestrado em Hidráulica e Recursos Hídricos) - Universidade Técnica de Lisboa, Lisboa 2002.

KANASHIRO, W.. Técnicas de laboratório para estudo em modelos reduzidos. In: COMITÊ BRASILEIRO DE BARRAGENS, SEMINÁRIO NACIONAL DE GRANDES BARRAGENS, 29. Anais. Porto de Galinhas, 2013.

LABITRIX. Canal de escoamento Hidráulico XL06. Itatiba, 2018.

MARQUES, J. C.; UNAS, M.. Estudos em modelo reduzido de percolação em barragens de aterro. Porto, 2010.
MELO L. R. T.. Monitoração de modelos físicos reduzidos para investigação do comportamento de estruturas em escala real. Dissertação (Mestrado em Estruturas e Geotecnia) - Universidade de São Paulo, São Paulo, 2011.

MENDONÇA, M. B.. Notas de aula da disciplina Obras de Terra. Rio de Janeiro, 2012.

QUINTAS, F. E. G.. Planeamento da Construção de Barragens de Terra. Dissertação (Mestrado em Vias de Comunicação) - Universidade do Porto, Porto, 2002.

RIBEIRO L. F. M.. Simulação física do processo de formação dos aterros hidráulicos aplicado a barragens de rejeitos. Tese (Doutorado em Geotecnia) - Universidade Federal de Brasília, Brasília, 2000.

SAYÃO, A.. Notas de aula da disciplina de Barragens de Terra e Enrocamento. Rio de Janeiro, 2009.

SOUZA, M. M.. Estudo para o projeto geotécnico da barragem de Alto Irani. Rio de Janeiro, 2013. 
VALENTE, O. F.; DIAS, H. C. T.. A Bacia Hidrográfica como Unidade Básica de Produção de Água. Revista Ação Ambiental, v.4, n.20, 2001.
VALVERDE, A. E. L.; MAFRA, J. W. A.; LOPES, N. L.. Princípios básicos do direito à preservação da água através do barramento de cursos d'água: construção de barragens para fins de agricultura irrigada, cenário regulatório. Viçosa, 2014.

A CBPC - Companhia Brasileira de Produção Científica (CNPJ: 11.221.422/0001-03) detém os direitos materiais desta publicação. Os direitos referem-se à publicação do trabalho em qualquer parte do mundo, incluindo os direitos às renovações, expansões e disseminações da contribuição, bem como outros direitos subsidiários. Todos os trabalhos publicados eletronicamente poderão posteriormente ser publicados em coletâneas impressas sob coordenação da Sustenere Publishing, da Companhia Brasileira de Produção Científica e seus parceiros autorizados. Os (as) autores (as) preservam os direitos autorais, mas não têm permissão para a publicação da contribuição em outro meio, impresso ou digital, em português ou em tradução. 